\title{
Liquid Chromatography Mass Spectrometry
}

National Cancer Institute

\section{Source}

National Cancer Institute. Liquid Chromatography Mass Spectrometry. NCI Thesaurus.

Code C18475.

LC/MS is a hyphenated technique, combining the separation power of liquid chromatography (LC), an analytical chromatographic technique for separating ions or molecules dissolved in a solvent, with the detection power of mass spectrometry(MS), a technique to separate gas phase ions according their $\mathrm{m} / \mathrm{z}$ (mass to charge ratio) value. Used for drug screening, pharmacology studies, environmental analyses and forensics. 